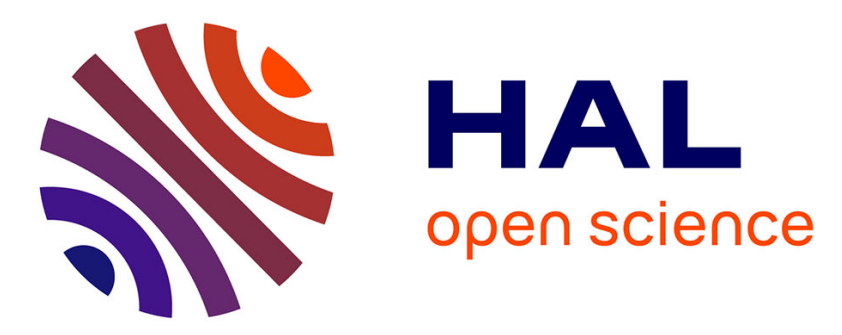

\title{
Data and Applications Security and Privacy XXXIV
}

Anoop Singhal, Jaideep Vaidya

\section{To cite this version:}

Anoop Singhal, Jaideep Vaidya. Data and Applications Security and Privacy XXXIV: 34th Annual IFIP WG 11.3 Conference, DBSec 2020, Regensburg, Germany, June 25-26, 2020, Proceedings. Springer International Publishing, LNCS-12122, 2020, Lecture Notes in Computer Science, 978-3-03049668-5. 10.1007/978-3-030-49669-2 . hal-03243621

\section{HAL Id: hal-03243621 \\ https://hal.inria.fr/hal-03243621}

Submitted on 31 May 2021

HAL is a multi-disciplinary open access archive for the deposit and dissemination of scientific research documents, whether they are published or not. The documents may come from teaching and research institutions in France or abroad, or from public or private research centers.
L'archive ouverte pluridisciplinaire HAL, est destinée au dépôt et à la diffusion de documents scientifiques de niveau recherche, publiés ou non, émanant des établissements d'enseignement et de recherche français ou étrangers, des laboratoires publics ou privés.

\section{(ㄷ)(1)}

Distributed under a Creative Commons Attribution| 4.0 International License 


\section{Lecture Notes in Computer Science}

Founding Editors

Gerhard Goos

Karlsruhe Institute of Technology, Karlsruhe, Germany

Juris Hartmanis

Cornell University, Ithaca, NY, USA

Editorial Board Members

Elisa Bertino

Purdue University, West Lafayette, IN, USA

Wen Gao

Peking University, Beijing, China

Bernhard Steffen (1)

TU Dortmund University, Dortmund, Germany

Gerhard Woeginger (1)

RWTH Aachen, Aachen, Germany

Moti Yung

Columbia University, New York, NY, USA 
More information about this series at http://www.springer.com/series/7409 
Anoop Singhal · Jaideep Vaidya (Eds.)

\section{Data and Applications Security and Privacy XXXIV}

34th Annual IFIP WG 11.3 Conference, DBSec 2020 Regensburg, Germany, June 25-26, 2020 Proceedings

黛 Springer 


\section{Editors}

Anoop Singhal

National Institute of Standards

and Technology

Gaithersburg, MD, USA

\author{
Jaideep Vaidya (iD \\ Rutgers University \\ Newark, NJ, USA
}

ISSN 0302-9743 ISSN 1611-3349 (electronic)
Lecture Notes in Computer Science
$\begin{array}{lll}\text { ISBN 978-3-030-49668-5 ISBN 978-3-030-49669-2 (eBook) } \\ \text { https://doi.org/10.1007/978-3-030-49669-2 }\end{array}$

LNCS Sublibrary: SL3 - Information Systems and Applications, incl. Internet/Web, and HCI

(C) IFIP International Federation for Information Processing 2020

This work is subject to copyright. All rights are reserved by the Publisher, whether the whole or part of the material is concerned, specifically the rights of translation, reprinting, reuse of illustrations, recitation, broadcasting, reproduction on microfilms or in any other physical way, and transmission or information storage and retrieval, electronic adaptation, computer software, or by similar or dissimilar methodology now known or hereafter developed.

The use of general descriptive names, registered names, trademarks, service marks, etc. in this publication does not imply, even in the absence of a specific statement, that such names are exempt from the relevant protective laws and regulations and therefore free for general use.

The publisher, the authors and the editors are safe to assume that the advice and information in this book are believed to be true and accurate at the date of publication. Neither the publisher nor the authors or the editors give a warranty, express or implied, with respect to the material contained herein or for any errors or omissions that may have been made. The publisher remains neutral with regard to jurisdictional claims in published maps and institutional affiliations.

This Springer imprint is published by the registered company Springer Nature Switzerland AG The registered company address is: Gewerbestrasse 11, 6330 Cham, Switzerland 


\section{Preface}

This volume contains the papers selected for presentation at the 34th Annual IFIP WG11.3 Conference on Data and Applications Security and Privacy (DBSec 2020), that was supposed to be during June 25-26, 2020, in Regensburg. While the conference was held on the dates as scheduled, due to the COVID-19 situation it was held virtually (for the first time in the history of DBSec), instead of physically in Regensburg.

In response to the call for papers of this edition, 41 submissions were received, and all submissions were evaluated on the basis of their significance, novelty, and technical quality. The Program Committee, comprising 40 members, performed an excellent job, with the help of additional reviewers, of reviewing all submissions through a careful anonymous process (three or more reviews per submission). The Program Committee's work was carried out electronically, yielding intensive discussions. Of the submitted papers, 14 full papers and 8 short papers were selected for presentation at the conference.

The success of DBSec 2020 depended on the volunteering effort of many individuals, and there is a long list of people who deserve special thanks. We would like to thank all the members of the Program Committee and all the external reviewers, for all their hard work in evaluating the papers and for their active participation in the discussion and selection process. We are very grateful to all people who readily assisted and ensured a smooth organization process, in particular Günther Pernul for his efforts as DBSec 2020 general chair; Sara Foresti (IFIP WG11.3 chair) for her guidance and support; Yuan Hong and Benedikt Putz (publicity chairs) for helping with publicity; and Petra Sauer for helping with other arrangements for the conference. EasyChair made the conference review and proceedings process run very smoothly.

Last but certainly not least, thanks to all the authors who submitted papers and all the conference attendees. We hope you find the proceedings of DBSec 2020 interesting, stimulating, and inspiring for your future research. 


\section{Organization}

\section{Program Committee}

\author{
Ayesha Afzal \\ Vijay Atluri \\ Frédéric Cuppens \\ Nora Cuppens-Boulahia \\ Sabrina De Capitani di \\ Vimercati \\ Giovanni Di Crescenzo \\ Csilla Farkas \\ Barbara Fila \\ Sara Foresti \\ Steven Furnell \\ Ehud Gudes \\ Yuan Hong \\ Sokratis Katsikas \\ Costas Lambrinoudakis \\ Adam J. Lee \\ Yingjiu Li \\ Giovanni Livraga \\ Javier Lopez \\ Brad Malin \\ Fabio Martinelli \\ Sjouke Mauw \\ Catherine Meadows \\ Charles Morisset \\ Martin Olivier \\ Stefano Paraboschi \\ Günther Pernul \\ Silvio Ranise \\ Indrajit Ray \\ Indrakshi Ray \\ Kui Ren \\ Pierangela Samarati \\ Andreas Schaad \\ Anoop Singhal \\ Scott Stoller \\ Shamik Sural \\ Jaideep Vaidya \\ Vijay Varadharajan
}

Air University, USA

Rutgers University, USA

Télécom Bretagne, France

IMT Atlantique, France

Università degli Studi di Milano, Italy

Perspecta Labs, USA

USC, USA

INSA Rennes, IRISA, France

Università degli Studi di Milano, Italy

Plymouth University, UK

Ben-Gurion University, Israel

Illinois Institute of Technology, USA

Open University of Cyprus, Cyprus

University of Piraeus, Greece

University of Pittsburgh, USA

University of Oregon, USA

University of Milan, Italy

UMA, Spain

Vanderbilt University, USA

IIT-CNR, Italy

University of Luxembourg, Luxembourg

NRL, USA

Newcastle University, UK

University of Pretoria, South Africa

Università di Bergamo, Italy

Universität Regensburg, Germany

FBK-Irst, Italy

Colorado State University, USA

Colorado State University, USA

State University of New York at Buffalo, USA

Università degli Studi di Milano, Italy

WIBU-Systems, Germany

NIST, USA

Stony Brook University, USA

IIT Kharagpur, India

Rutgers University, Australia

The University of Newcastle, Australia 
Lingyu Wang

Wendy Hui Wang

Edgar Weippl

Attila A. Yavuz

Nicola Zannone

\section{Additional Reviewers}

Alcaraz, Cristina

Berlato, Stefano

Binder, Dominik

Bursuc, Sergiu

Chen, Xihui

Clark, Stanley

Derbeko, Philip

Georgiopoulou, Zafeiroula

Groll, Sebastian

Haefner, Kyle

Liu, Bingyu

Liu, Yongtai

Lyvas, Christos
Concordia University, Canada

Stevens Institute of Technology, USA

University of Vienna, Austria

University of South Florida, USA

Eindhoven University of Technology, The Netherlands
Mohamady, Meisam

Mykoniati, Maria

Nieto, Ana

Roman, Rodrigo

Sascha, Kern

Schlette, Daniel

Sciarretta, Giada

Shafiq, Basit

Thang, Hoang

Voloch, Nadav

Wan, Zhiyu

Wang, Han

Yan, Chao 


\section{Contents}

\section{Network and Cyber-Physical Systems Security}

Modeling and Mitigating Security Threats in Network Functions

Virtualization (NFV) . . . . . . . . . . . . . . . . . . . . . . . . . . .

Nawaf Alhebaishi, Lingyu Wang, and Sushil Jajodia

Managing Secure Inter-slice Communication in 5G Network Slice Chains . . .

Luis Suárez, David Espes, Frédéric Cuppens, Cao-Thanh Phan, Philippe Bertin, and Philippe Le Parc

Proactively Extracting IoT Device Capabilities: An Application

to Smart Homes . . . . . . . . . . . . . . . . . . . . . . . . . . . . . .

Andy Dolan, Indrakshi Ray, and Suryadipta Majumdar

Security Enumerations for Cyber-Physical Systems . . . . . . . . . . . . . .

Daniel Schlette, Florian Menges, Thomas Baumer, and Günther Pernul

\section{Information Flow and Access Control}

Inference-Proof Monotonic Query Evaluation

and View Generation Reconsidered.....................

Joachim Biskup

Network Functions Virtualization Access Control as a Service . . . . . . . . . .

Manel Smine, David Espes, Nora Cuppens-Boulahia, and Frédéric Cuppens

Effective Access Control in Shared-Operator Multi-tenant Data Stream

Marian Zaki, Adam J. Lee, and Panos K. Chrysanthis

Information Flow Security Certification for SPARK Programs . . . . . . . .

Sandip Ghosal and R. K. Shyamasundar

\section{Privacy-Preserving Computation}

Provably Privacy-Preserving Distributed Data Aggregation in Smart Grids . . .

Marius Stübs, Tobias Mueller, Kai Bavendiek, Manuel Loesch,

Sibylle Schupp, and Hannes Federrath

Non-interactive Private Decision Tree Evaluation . . . . . . . . . . . . 
Privacy-Preserving Anomaly Detection Using Synthetic Data . . . . . . . . . .

Rudolf Mayer, Markus Hittmeir, and Andreas Ekelhart

Local Differentially Private Matrix Factorization

with MoG for Recommendations.

Jeyamohan Neera, Xiaomin Chen, Nauman Aslam, and Zhan Shu

\section{Visualization and Analytics for Security}

Designing a Decision-Support Visualization for Live Digital

Forensic Investigations. . . . . . . . . . . . . . . . . . . . . . .

Fabian Böhm, Ludwig Englbrecht, and Günther Pernul

Predictive Analytics to Prevent Voice over IP International

Revenue Sharing Fraud .......................

Yoram J. Meijaard, Bram C. M. Cappers, Josh G. M. Mengerink, and Nicola Zannone

PUA Detection Based on Bundle Installer Characteristics. . . . . . . . . . . . . . Amir Lukach, Ehud Gudes, and Asaf Shabtai

ML-Supported Identification and Prioritization of Threats in the OVVL Threat Modelling Tool . . . . . . . . . . . . . . . . . . . . Andreas Schaad and Dominik Binder

\section{Spatial Systems and Crowdsourcing Security}

Enhancing the Performance of Spatial Queries on Encrypted

Data Through Graph Embedding. . . . . . . . . . . . . . . . . .

Sina Shaham, Gabriel Ghinita, and Cyrus Shahabi

Crowdsourcing Under Data Poisoning Attacks: A Comparative Study . . . . . .

Farnaz Tahmasebian, Li Xiong, Mani Sotoodeh, and Vaidy Sunderam

Self-enhancing GPS-Based Authentication Using Corresponding Address. . . .

Tran Phuong Thao, Mhd Irvan, Ryosuke Kobayashi,

Rie Shigetomi Yamaguchi, and Toshiyuki Nakata

\section{Secure Outsourcing and Privacy}

GOOSE: A Secure Framework for Graph Outsourcing and SPARQL Evaluation . . . . . . . . . . . . . . . . . . .

Radu Ciucanu and Pascal Lafourcade

SGX-IR: Secure Information Retrieval with Trusted Processors. . . . . . . . . . 
Readability of Privacy Policies . . . . . . . . . . . . . . . . . . . . 388 Barbara Krumay and Jennifer Klar 